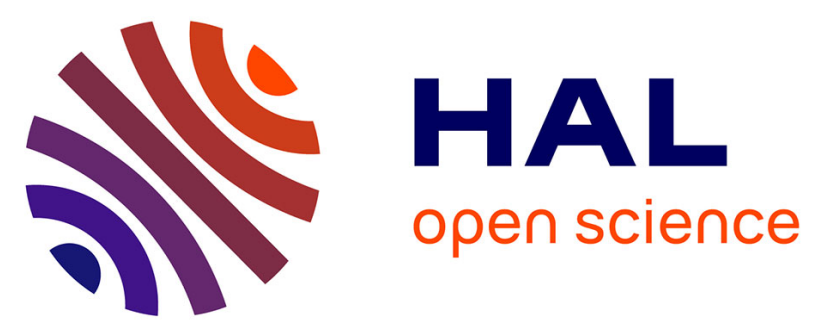

\title{
Effects of in vitro shocks and hydrothermal degradation on wear of ceramic hip joints: Towards better experimental simulation of in vivo ageing
}

Armelle Perrichon, Bruno Reynard, Laurent Gremillard, Jérome Chevalier, Frédéric Farizon, Jean Geringer

\section{To cite this version:}

Armelle Perrichon, Bruno Reynard, Laurent Gremillard, Jérome Chevalier, Frédéric Farizon, et al.. Effects of in vitro shocks and hydrothermal degradation on wear of ceramic hip joints: Towards better experimental simulation of in vivo ageing. Tribology International, 2016, 42nd Leeds-Lyon Symposium on Tribology- Surfaces and Interfaces: Mysteries at Different Scales, 100, pp.410-419. 10.1016/j.triboint.2016.05.010 . hal-01342571

\section{HAL Id: hal-01342571 \\ https://hal.science/hal-01342571}

Submitted on 6 Jul 2016

HAL is a multi-disciplinary open access archive for the deposit and dissemination of scientific research documents, whether they are published or not. The documents may come from teaching and research institutions in France or abroad, or from public or private research centers.
L'archive ouverte pluridisciplinaire HAL, est destinée au dépôt et à la diffusion de documents scientifiques de niveau recherche, publiés ou non, émanant des établissements d'enseignement et de recherche français ou étrangers, des laboratoires publics ou privés. 


\title{
Effects of in vitro shocks and hydrothermal degradation on wear of ceramic hip joints: towards better experimental simulation of in vivo ageing
}

\author{
Armelle Perrichon $^{\mathrm{a}, \mathrm{b}^{\star}}$, Bruno Reynard $^{\mathrm{c}}$, Laurent Gremillard ${ }^{\mathrm{d}}$, Jérôme Chevalier ${ }^{\mathrm{d}}$, Frédéric Farizon $^{\mathrm{e}}$, \\ Jean Geringer ${ }^{a, b}$ \\ *armelle.perrichon@emse.fr, corresponding author \\ ${ }^{a}$ Ecole Nationale Supérieure des Mines de Saint-Etienne, CIS-EMSE, SAINBIOSE, INSERM U1059, F- \\ 42023 Saint-Etienne, Fance \\ bUniversité de Lyon, F-69000 Lyon, France \\ 'Laboratoire de Géologie de Lyon, Université de Lyon, Ecole Normale Supérieure de Lyon, Université \\ Claude Bernard Lyon 1, CNRS, 46 Allée d'Italie, 69364 Lyon Cedex 07, France \\ 'Université de Lyon, INSA-Lyon, MATEIS, UMR CNRS 5510, 20 Avenue Einstein, 69621 Villeurbanne, \\ France \\ ${ }^{\text {e}}$ Chirurgie Orthopédique et Traumatologie, CHU Saint-Etienne, Avenue Albert Raimond, 42270 Saint- \\ Priest-en-Jarez, France
}

\begin{abstract}
In an ageing world population, increasing the lifetime of orthopedic devices is of vital importance for reducing surgical risks for patients and reducing medical costs. Ceramic materials are gaining interest because of their hardness and chemical inertia with respect to metal prosthesis. Wear of the prosthetic couple (femoral head and cup) is one of the main rationales for using ceramic hip implants, because they induce much lower wear debris. The present study investigates the combined effects of shocks due to microseparation and hydrothermal ageing on the wear of Zirconia Toughened Alumina (ZTA) bearings, which have been under strong development these past ten years. Wear stripe patterns are formed on femoral heads tested on a shock device. 3D profilometry is used to evaluate the volume of worn material released from the head that averages at $0.46 \mathrm{~mm}^{3} /$ year during simulation mimicking about 15 years of ageing. This volume is larger than formerly estimated with hip walking simulators with microseparation, an effect that we tentatively attribute to a larger force $(9000 \mathrm{~N})$ applied here than on hip simulators where the force was not specified. The present experiment should allow refining the effect of force on the wear of ceramic femoral head, hence to simulate different patient conditions (weight, activity, accidents,...). Micro Raman spectroscopy reveals significant zirconia phase transformation within wear stripes. ZTA components show minor phase transformation during hydrothermal degradation in an autoclave when compared to changes induced by shocks. Finally, five clinically retrieved bearings are characterized for in vivo comparison, and also reveal phase transformation within wear track areas. The association of phase transformation enhancement with wear areas on in vivo samples indicates that wear is induced by shocks, rather than by hydrothermal ageing. Shock simulations are therefore essential for in vitro experimentation aiming at reproducing wear of ceramic implants and in vivo environment. On a material's point of view, it is shown that the ZTA ceramics can exhibit a beneficial phase transformation under stress, which may limit wear stripes, without suffering from significant ageing.
\end{abstract}




\section{Introduction}

Increasing hip implant lifetime is a challenge for limiting surgery in an ageing world population, health risks for patients and costs for health agencies. For this purpose, it is necessary to improve the resistance of hip joint components (femoral head and cup) to corrosion, wear and failure. Corrosion is a concern with metal hip implants that can be circumvented by the use of bio-inert ceramic materials that were introduced in total hip arthroplasty in the 1970's [1]. The higher resistance of Ceramic-on-Ceramic $(\mathrm{CoC})$ bearings to wear degradation compared to more commonly employed Metal-on-Polymer (MoP) or Metal-on-Metal (MoM) ones was demonstrated by in vitro experiments on hip walking simulators [2] and by clinical evidence [3]. First ceramic implants were prone to failure, a problem that was solved by improving material properties, manufacturing and component design [3].

Alumina and zirconia have been employed in orthopedics under various bearing configurations. Nowadays, a composite based on an alumina matrix and containing zirconia grains (mostly between $5 \%$ vol. and $30 \%$ vol.) and other additives, known as Zirconia Toughened Alumina (ZTA), is used [4]. Wear of ceramics, even if much lower than with other bearings, remains a concern because it releases debris leading to osteolysis and aseptic loosening. The tribological properties of such materials must be improved in order to increase the typical implant lifetime from about 10-15 years to ideally up to 40 years. Finally, hydrothermal alteration of zirconia based ceramics in contact with body fluid [5], although less severe than chemical degradation of metals, must be taken into account over such long periods.

Because clinical tests take decades, it is desirable to build experimental and theoretical models of ceramic wear in hip implants. Currently, hip walking simulators are the most commonly used devices to investigate the wear resistance of hip implants. Friction occurring during walking is reproduced according to the 14242-1 ISO standard [6] which gives details of the usual hip movements such as abduction/adduction, external/internal rotations and flexion/extension. Besides wear caused by friction, hard-on-hard bearings such as CoC or MoM are sensitive to shock degradation. Dennis et al. [7] demonstrated through in vivo video fluoroscopy of implanted hip joints the periodic occurrence of a small separation between the femoral head and cup. This phenomenon, called microseparation, generates shocks that are not reproduced by standard gait cycles on hip walking simulator. Modified hip walking simulators including microseparation conditions have been developed to take into consideration this phenomenon [8].

Better modeling of hip implant wear requires investigating the effects of shock in order to reproduce the behavior in patients of various body mass index and activity. Current experimental setups do not allow varying independently friction and shock intensity. A shock machine was thus developed to subject prosthetic components to controlled and imposed load force and microseparation value [9]. Wear stripe patterns similar to the ones clinically observed were reproduced on ceramic components and wear rates were compared to the literature [10]. Highest stresses on both femoral head and cup were located and quantified through a finite element modeling simulation [11] and allowed a better understanding of the mechanism of wear stripe patterns formation. 
We used this procedure to systematically investigate the long-term effects of shocks due to microseparation. Both shock and hydrothermal alteration may contribute to wear and to a phase transition from tetragonal to monoclinic in zirconia [12]. We studied the combined effects of shock and hydrothermal ageing by alternatively submitting implants to shock and alteration cycles. We produced in vitro simulated explants having undergone up to 1.5 millions shocks and hydrothermal alteration corresponding to about 15 years of human activity. Wear is quantified using 3D profilometry and phase transformation is characterized with Raman spectroscopy. Results are used to discuss the relative influence of shock, hydrothermal alteration and friction on wear of ceramic hip implants. Clinically retrieved implants were also analyzed with a view to investigating correlations between in vitro and in vivo behavior and further adjusting in vitro testing procedures.

\section{Materials and Methods}

\subsection{Test specimens}

Several prosthetic couples (36mm diameter femoral heads and the corresponding cups) were provided by CeramTec AG (Plochingen, Germany) to be tested. They are made of zirconia toughened alumina (ZTA), consisting mainly of an alumina matrix containing zirconia grains.

In parallel retrieved implants were analyzed for comparison with in vivo wear. They consist of four ZTA articulating components (cases \#1 to \#4) and one set of yttria stabilized zirconia bearings (case \#5). Table 1 summarizes material and design characteristics of the bearing components and their respective wear conditions. The retrieved implants were macroscopically examined for first approximation determination of worn and unworn areas before performing detailed surface characterization.

\begin{tabular}{|c|c|c|c|c|c|}
\hline Case & $\begin{array}{l}\text { Head } \\
\text { type }\end{array}$ & $\begin{array}{l}\text { Head } \\
\text { diameter } \\
(\mathrm{mm})\end{array}$ & Cup type & Head conditions & Cup conditions \\
\hline \#1 & ZTA & 36 & ZTA & 1 wear stripe & Intact \\
\hline \#2 & ZTA & 32 & $\overline{\mathrm{ZTA}}$ & $\begin{array}{c}1 \text { wear stripe } \\
\text { Metallic tracks }\end{array}$ & Metallic tracks \\
\hline \#3 & ZTA & 36 & $\overline{\mathrm{ZTA}}$ & $\begin{array}{c}1 \text { wear stripe } \\
\text { Few metallic tracks }\end{array}$ & $\begin{array}{c}1 \text { wear stripe on the rim - } \\
\text { Few metallic tracks - } \\
\text { Signs of cup mobility within } \\
\text { metal-back }\end{array}$ \\
\hline \#4 & ZTA & 36 & ZTA & 1 wear stripe & $\begin{array}{l}\text { Signs of cup mobility within } \\
\text { metal-back }\end{array}$ \\
\hline$\# 5$ & $\begin{array}{c}\text { Yttria } \\
\text { stabilized } \\
\text { zirconia }\end{array}$ & 32 & $\begin{array}{l}\text { Sandwich } \\
\text { structure } \\
\text { zirconia/ } \\
\text { UHMWPE }\end{array}$ & 4 wear zones & $\begin{array}{c}\text { Wear zones on zirconia cup } \\
\text { - Impingement signs on } \\
\text { UHMWPE cup }\end{array}$ \\
\hline
\end{tabular}

Table 1: Material and design characteristics and first observation of wear conditions of the five clinically retrieved implants under study. 


\subsection{Shock machine device}

A shock device has been specifically designed to test the bearing components of a hip prosthesis under controlled microseparation conditions [9]. The femoral head and cup assembly was inclined at $45^{\circ}$ corresponding to average anatomical conditions. In previous studies on the same device [10], [11], [13] implants were fixed with cement, which resulted in problems due to compaction. Here, the cup was screwed on the holding support, and the head was mounted onto a cone composed of Ti-6Al-4V alloy in order to control and repeat more accurately the fixation of both components.

The tests were conducted in a fetal bovine serum solution $\left(B i o W e s t^{\circledR}\right.$ ) diluted in water (protein concentration of $30 \mathrm{~g} / \mathrm{L}$ ) and replaced weekly with fresh lubricant to avoid protein degradation [6]. The temperature of the solution was monitored, and deviated from in vivo $37^{\circ} \mathrm{C}$ as a consequence of the device heating by an average of $+5^{\circ} \mathrm{C}$. However the temperature was strictly maintained well below $50^{\circ} \mathrm{C}$, above which severe degradation and/or coagulation of proteins occurs in bovine serum.

The ceramic bearings were subjected to shocks under a typical load-profile illustrated in Figure 1. A microseparation of $1.3 \mathrm{~mm}$ (i.e. $1 \mathrm{~mm}$ along the vertical axis) was imposed between the head and the cup. Each prosthetic couple was submitted to $1.5 \mathrm{M}$ shocks at a frequency of $1.2 \mathrm{~Hz}$. The frequency has been controlled according to the test duration. Shocks consisted of applying a maximum load of $9000 \mathrm{~N}$ between the two components as a result of the head displacement in the vertical direction. This displacement had to be adjusted during the testing procedure in order to overcome the fatigue of the hydraulic system. The width of the peaks, i.e. the duration of the shocks, reached about $30 \mathrm{~ms}$ and it was followed by a damping stage. This latter is due to the movement of the cup in the horizontal direction and illustrates the elastic response (compliance) of the device supporting the cup after impact. Additional peaks at low mechanical load (less than $100 \mathrm{daN}$ ) may appear as a consequence of the elastic rebound of the machine: they were not taken into account as shocks, since they occur at much lower loads than the major peak load.

The load applied here $(9000 \mathrm{~N})$ means approximately 600\%BW (body weight) for a patient who weights $150 \mathrm{~kg}$ and may occur when climbing stairs rapidly. Contact forces between the head and cup had been measured on instrumented implants and reached 150 to $480 \%$ BW depending on the walking speed; it was also considered that this force may be $20 \%$ higher when climbing stairs than during normal walking [13]. The worst case of degradation by shocks is here under study. 

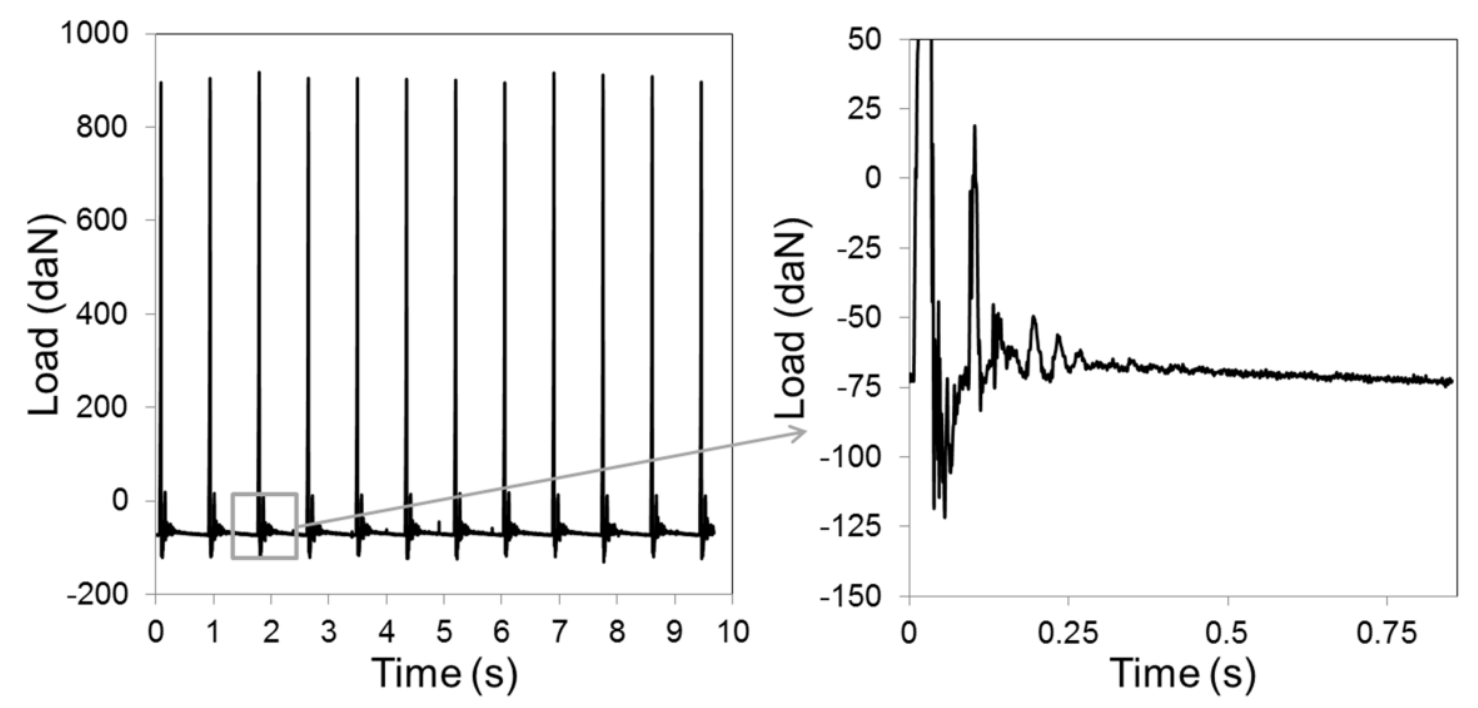

Figure 1: Left: typical load-profile applied between the femoral head and cup on the shock device. Right: details of a damping stage illustrating the elastic response of the device after impact.

\subsection{Hydrothermal ageing tests}

The prosthetic components were submitted to artificial ageing tests according to the ISO standard 13356 procedure for ceramic implants based on yttria stabilized zirconia (3Y-TZP)[14]. Both heads and cups were placed in an autoclave (Micro 8, 4001745, autoclave MED8, JP Selecta S.A) in water steam at $134^{\circ} \mathrm{C}$ and 2 bars. One hour of artificial ageing represents roughly 2-4 years of in vivo hydrothermal ageing [5].

\subsection{Conditions of tests}

This study seeks to reproduce at best the in vivo environment by combining the shock and hydrothermal degradation mechanisms. The mechanical stresses applied on the shock machine are roughly those induced by walking up and down stairs. As a consequence, it is estimated that 100,000 shocks performed in vitro simulate one year of human activity, i.e. walking up and down fifteen stairs eighteen times every day. In parallel, one year of in vivo hydrothermal degradation is simulated by one hour of accelerated ageing in an autoclave. The notion of simulated in vivo time is introduced in correlation with in vitro testing time according to these estimations.

Various combinations of in vitro tests were performed in this study (Table 2). Two bearings (cases \#a and \#b) underwent only shocks under severe conditions (9000 N) and a third one (case \#c) was alternatively subjected to hydrothermal ageing in an autoclave for 0.5 hour every 50,000 shocks. In parallel, two additional femoral heads were submitted only to in vitro hydrothermal degradation. One of them (case \#d) was periodically aged for small time increments (2.5 hours during the first 15 hours). The second one (case \#e) was directly submitted to many successive hours in the autoclave in order to investigate a potential effect of 
the number of cumulative ageing steps. At the end of the tests, both cases experienced a total of 110 hours in the autoclave.

\begin{tabular}{|c|c|c|}
\hline Case & Number of shocks (M) & Hydrothermal ageing (hour) \\
\hline$\#$ a & 1.5 & 0 \\
\hline$\# \mathbf{b}$ & 1.5 & 0 \\
\hline$\# \mathbf{c}$ & 1.5 & 15 \\
\hline$\# \mathbf{d}$ & 0 & 110 \\
\hline$\# \mathbf{e}$ & 0 & 110 \\
\hline
\end{tabular}

Table 2: Summary of the in vitro tests performed on ZTA prosthetic components. Shocks are performed at $9000 \mathrm{~N}$ on the shock device and hydrothermal ageing in an autoclave is performed at $134^{\circ} \mathrm{C}$ and 2 bars in water steam.

A surface characterization was carried out regularly with non-destructive techniques. The wear volume was estimated by 3D profilometry every 250,000 shocks and micro Raman spectroscopy was employed to assess the zirconia phase transformation.

\subsection{Protocol for measuring the wear volume}

A new method based on 3D profilometry (Bruker nanoscope ${ }^{T M}$, ex. Veeco, Wyko NT 9100) and data analysis on Matlab ${ }^{\circledR}$ was developed for measuring the wear volume resulting from the creation of wear stripe patterns on the ceramic femoral heads. Gravimetric methods were avoided here because weight loss is limited on ceramic bearings and the measured loss often arises from the mechanical release of other material than the femoral head, such as the metallic support or cone. 3D profilometry is a non-destructive technique that measures the surface topography using white-light interferometry. The acquisition of interferometric images and the comparison with the unworn femoral head spherical profile are the main stages of this method.

The depth and width of the wear stripes could vary along their length and be significantly different depending on the test conditions. In order to take into consideration the wear stripe heterogeneity, several images of the whole stripe width were taken all around the femoral head. Typically one image every 15 degrees, i.e. a total of 24 images per head, was taken by rotation on a custom-made holder (Figure 2). From these images, the wear areas were calculated by collecting 2D profiles by using the profilometer software (Vision 4.20 2002-2008 Veeco Instruments, Inc).

On the collected 2D stripe profiles, a tilt removal was applied but no filter was employed to correct the spherical shape of the femoral head since this latter is required for the interpolation. For each image, i.e. each location, three profiles were exported in Matlab ${ }^{\circledR}$ in order to obtain one mean smoothed profile from which the wear area was calculated. The sphere center and radius of the unworn femoral head were calculated by a least squared fitting procedure [15] using the profile points outside of the wear stripe. The wear area was calculated by subtraction between unworn profile and the measured profile. For each location, the wear volume was obtained by multiplying the wear area by the part of the stripe length considered. Finally, the total wear volume was calculated by summing up all the local wear volumes. 


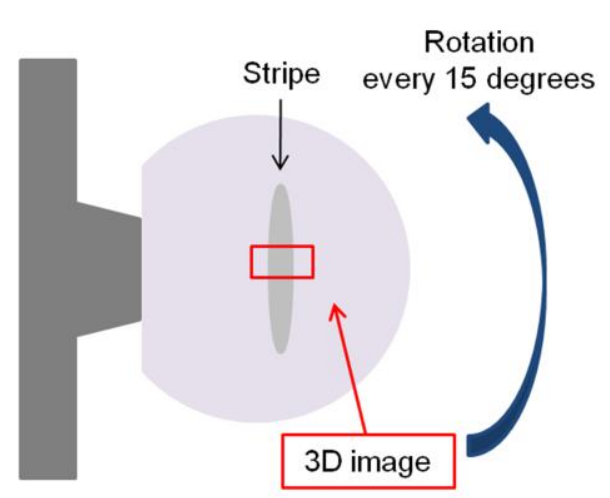

1 - 3D images acquisition of the whole stripe width

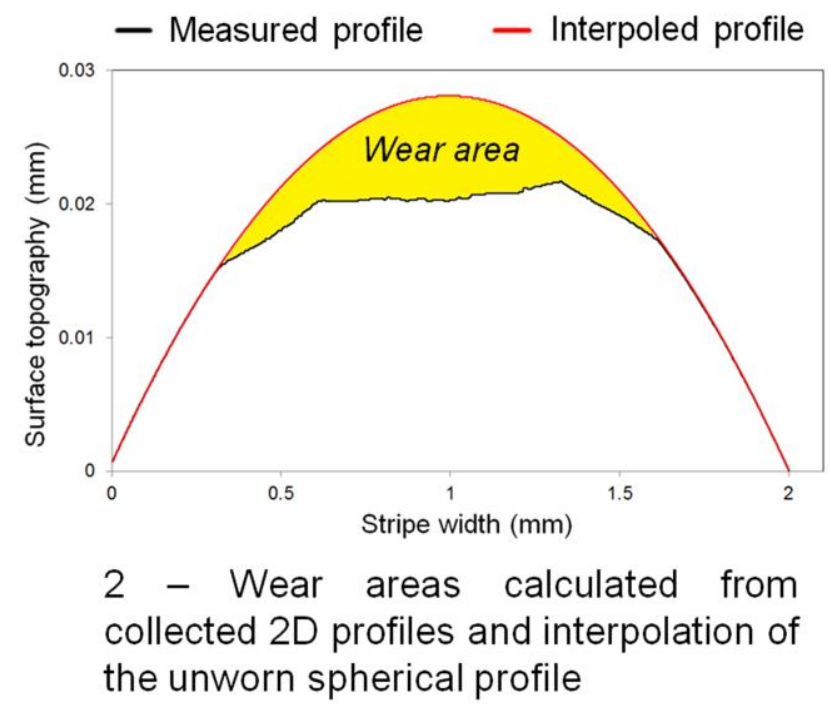

Figure 2: Two main stages for measuring the wear volume resulting from wear stripe patterns on ceramic femoral heads. First, several 3D images are taken regularly in order to take into account stripe heterogeneity. Second, wear areas are calculated from averaged $2 D$ profiles and interpolation of the unworn femoral head spherical profile shape.

\subsection{Analysis of the zirconia phase transformation}

The zirconia phase transformation was measured by micro Raman spectroscopy (Horiba Jobin Yvon HR800, laser $\lambda=514.5 \mathrm{~nm}$ ) on the femoral head surfaces. The laser power was set at $\sim 50 \mathrm{~mW}$ and the spectrum integration time was usually $12 \mathrm{~s}$ repeated 3 times for averaging. By varying the integration time, it was confirmed that the laser irradiation and sample heating did not occur or disturb the phase composition. The samples were positioned on a monitoring platform whose movements in $\mathrm{x}$ and $\mathrm{y}$ directions are computer-controlled.

Four characteristics peaks are used to distinguish zirconia polymorphs. Their intensities are related to the monoclinic volume fraction, $\mathrm{V}_{\mathrm{m}}$, according to Clarke and Adar formula [16]:

$$
V m(\%)=\frac{I_{m}^{178}+I_{m}^{189}}{0.97 \times\left(I_{t}^{145}+I_{t}^{256}\right)+I_{m}^{178}+I_{m}^{189}} \times 100
$$

where Im and It represent the intensities of the monoclinic and tetragonal phase peaks, respectively, with the related wave numbers in superscript (Figure 3). Raman spectra were exported in Matlab ${ }^{\circledR}$ and the baseline was corrected using a function developed by Mazet et al. [17]. 


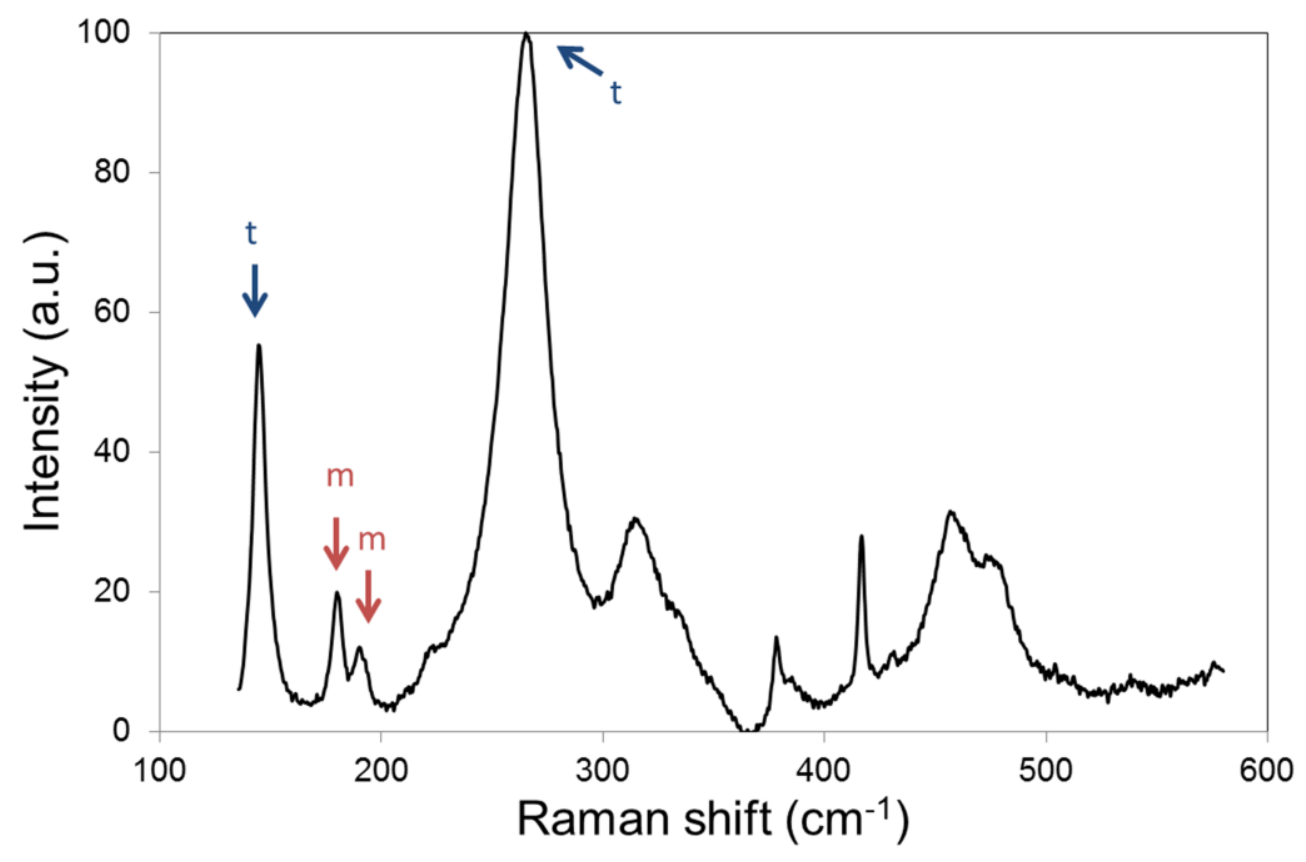

Figure 3: Raman spectrum of a ZTA femoral head; arrows indicate the four characteristics peaks used to distinguish monoclinic $(m)$ and tetragonal $(t)$ zirconia phases and whose intensities are employed to calculate the monoclinic volume fraction, $V_{m}$.

A potential increase of the monoclinic content due to mechanical or hydrothermal stresses was investigated on the femoral head surfaces. For a better statistical analysis, at least 10 measurements were carried out to average the monoclinic content within the wear stripes. Outside of them, i.e. on unworn surface, the phase transformation was assessed at the pole and at latitudes $45^{\circ}, 90^{\circ}$ and $105^{\circ}$ (four measurements at each latitude and uniformly distributed by a rotation of the femoral head) (Figure 4). A specific femoral head holder has been developed in order to repeat the same positioning, i.e. latitude and angle of rotation of a femoral head, between each step of a whole test (every 250,000 shocks). 


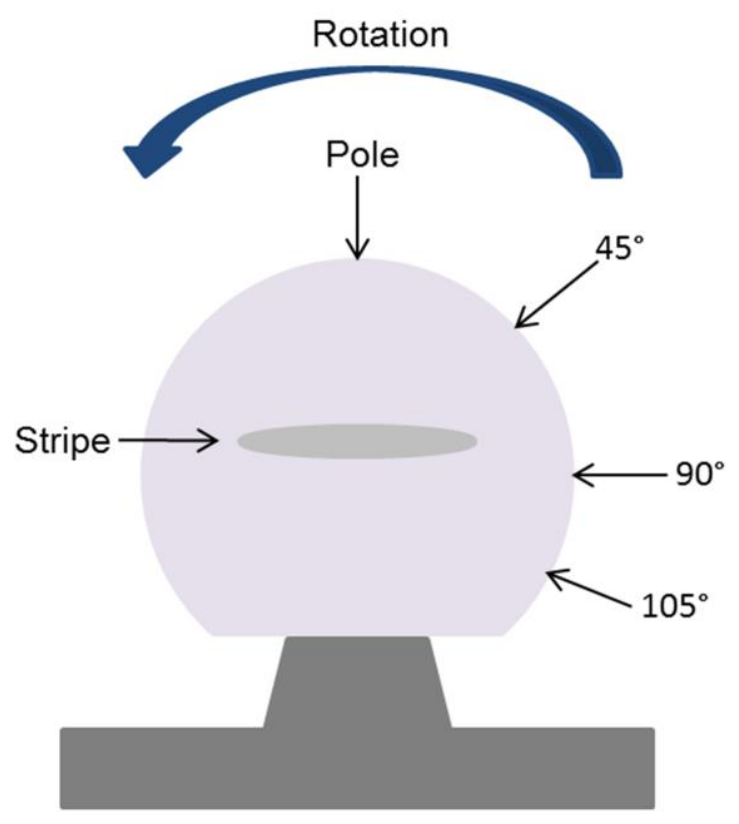

Figure 4: Micro Raman spectroscopy and surface roughness analysis carried out at several locations outside of stripe; visualization of the mean location of the wear stripe obtained on the shock device.

\subsection{Analysis of the surface roughness}

The femoral heads surface roughness was obtained by 3D profilometry at the same locations as in the micro Raman spectroscopy analysis (Figure 4). A filter was applied by using the profilometer software in order to remove the spherical shape of the head. The roughness parameter $S_{a}$ was evaluated on each acquired image. It is the arithmetic average of the 3D surface roughness and represents an overall measurement of the texture comprising the surface. It is calculated from the absolute values of height, $Z(x, y)$, measured in the analyzed area, A:

$$
S a=\frac{1}{A} \iint_{A}|Z(x, y)| d x d y
$$

\section{Results}

\subsection{Surface morphology and wear stripes}

The femoral heads and cups submitted to a severe-shock degradation at $9000 \mathrm{~N}$ (cases \#a to \#c) exhibit wear degradation but no fracture. Two wear stripes were observed on each head, with corresponding worn areas on the rim of the cups. The main stripe (upper one) is a direct consequence of shocks between the two components and the second one (lower one) is due to rebounds following the main shock [10]. At the end of the test, i.e. after $1.5 \mathrm{M}$ shocks or 15 
simulated in vivo years, the upper stripes width ranged between 3.5 and $5.4 \mathrm{~mm}$ and averaged $4.5 \mathrm{~mm}$ (Figure 5). The lower stripes were significantly narrower and ranged between 0.8 and $3.3 \mathrm{~mm}$ (average is $2.8 \mathrm{~mm}$ ).

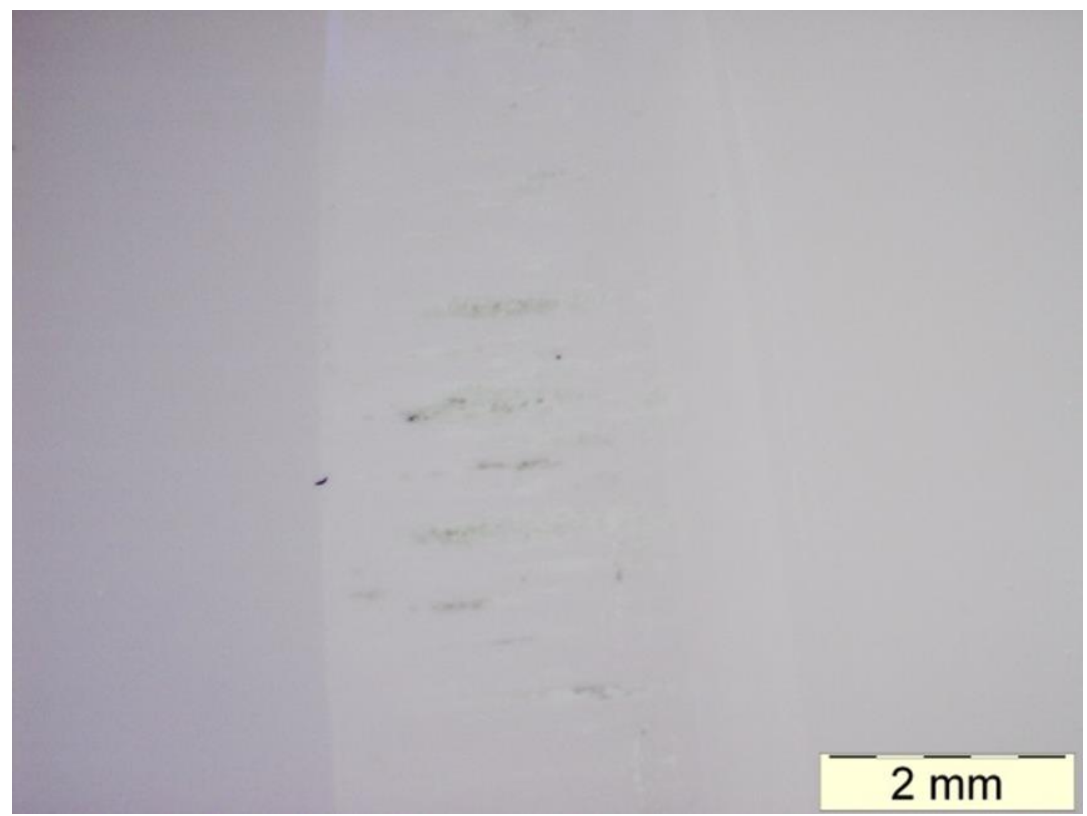

Figure 5: A typical upper wear stripe obtained on a femoral head after performing test on the shock machine; the stripe width reached almost $4 \mathrm{~mm}$.

The analysis of 3D images revealed an increase of surface roughness within the worn areas, in particular to due pitting. Scattered values of $S_{a}$ parameter ranged between $30 \mathrm{~nm}$ and several hundred of $\mathrm{nm}$. In contrast, $S_{\mathrm{a}}$ remained at a nearly constant value close to $12 \mathrm{~nm}$ outside of stripes (Figure 6). The filtering process generated to remove the spherical shape of the heads led to the observation of artifacts on the images that are associated with waviness created by the interferences fringes. In order to not remove any topographic features measured on the surfaces, we did not modify the images. However we confirmed that the artifacts do not affect the relative evolution of $S_{a}$, in particular for the smoother unworn areas. 

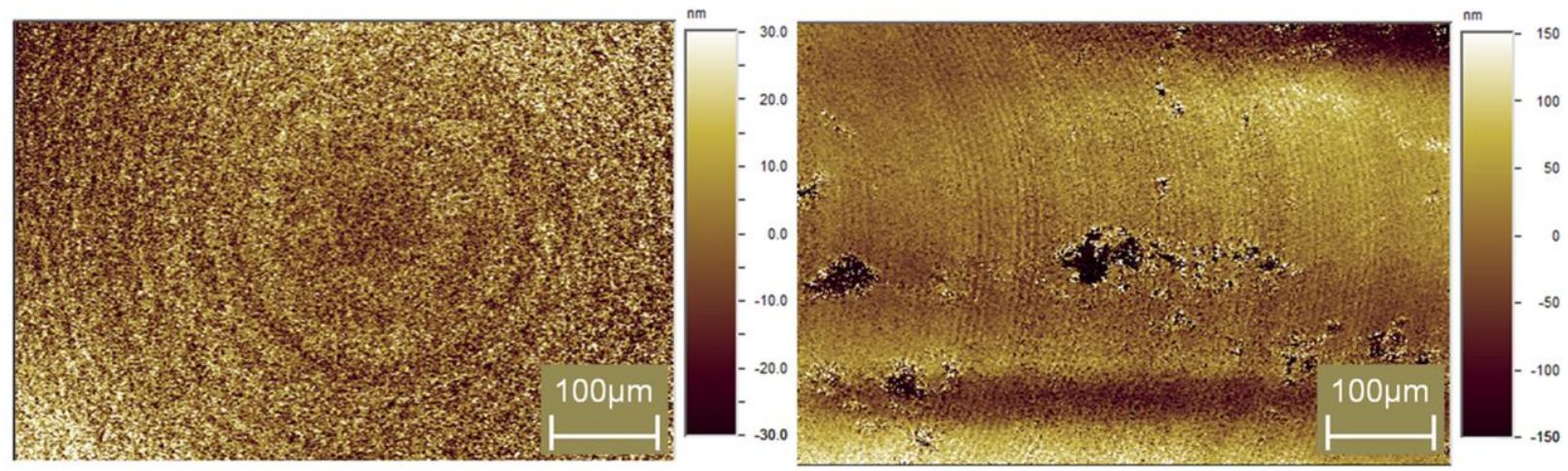

Figure 6: Images obtained by 3D profilometry for surface roughness evaluation; a) outside of stripe, i.e. pristine ZTA, $S_{a}=11.76 \mathrm{~nm}$ b) within stripe, $S_{a}=46.25 \mathrm{~nm}$.

\subsection{Wear quantification and characterization}

The formation of the wear stripe patterns under shock condition results in an important wear volume and wear debris release. Systematic collection of wear debris from a synovial solution is impractical and cannot be used to directly assess the wear quantification. An isolated debris was observed by scanning electron microscopy (MEB FEG ZEISS SUPRA 55 VP) (Figure 7). The brightest grains are zirconia and the darkest ones are alumina. The main observation is the dominance of inter-granular fracture, which is thought to dominate wear debris formation.

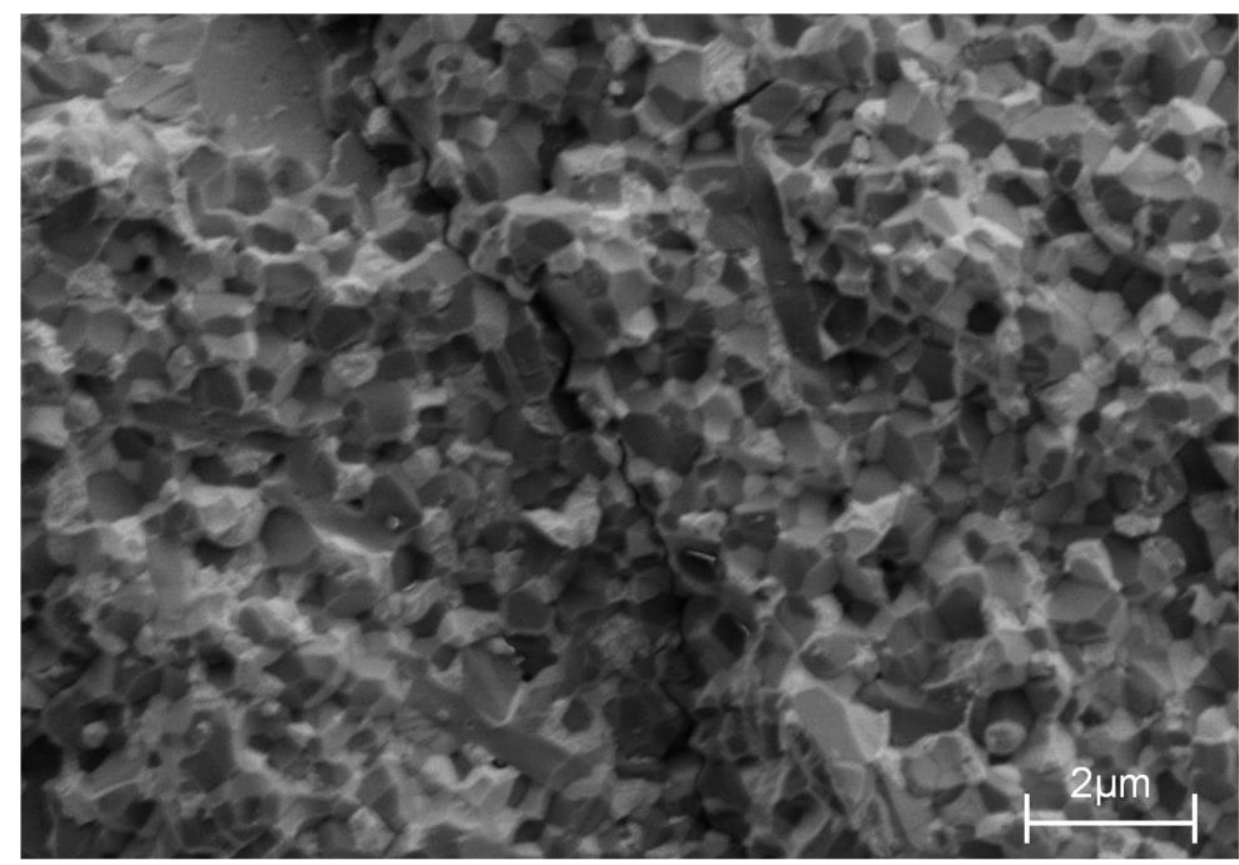

Figure 7: Image of an isolated wear debris produced during in vitro tests on the shock device. Inter-granular fracture of both zirconia and alumina grains is observed. 
The wear volumes were quantified by $3 \mathrm{D}$ profilometry and reached several $\mathrm{mm}^{3}$ after $1.5 \mathrm{M}$ shocks or 15 simulated in vivo years. Three bearings were tested in vitro under the same mechanical conditions (Table 2). For each test, the wear volume was calculated every 250,000 shocks with an estimated relative uncertainty of $10 \%$. From the observation of the three wear volume trends (Figure 8) two distinct phases were determined according to the testing time. An initial phase was defined up to 500,000 shocks, i.e. 5 simulated in vivo years. It corresponded to the highest wear volumes and stripes width increase. From 500,000 shocks to the end of the tests, a nearly steady phase was observed with little wear volumes and stripes width evolution.

It is worth noting that identified experimental accidents occurred during long-term experiments on cases \#a and \#b. Case \#a suffered from the rupture of a metallic part of the shock machine between 0.25 and $0.5 \mathrm{M}$ shocks and leading to a momentary lower shock absorption. The hydraulic pressure of the device temporarily experienced a fluctuation at the beginning of the test on the case \#b, which led to the release of localized large grain aggregates (several hundred $\mu \mathrm{m}$ ). We suspect micro-cracks being created around those localized areas to be at the origin of a high wear volume release carrying on up to the end of the test.

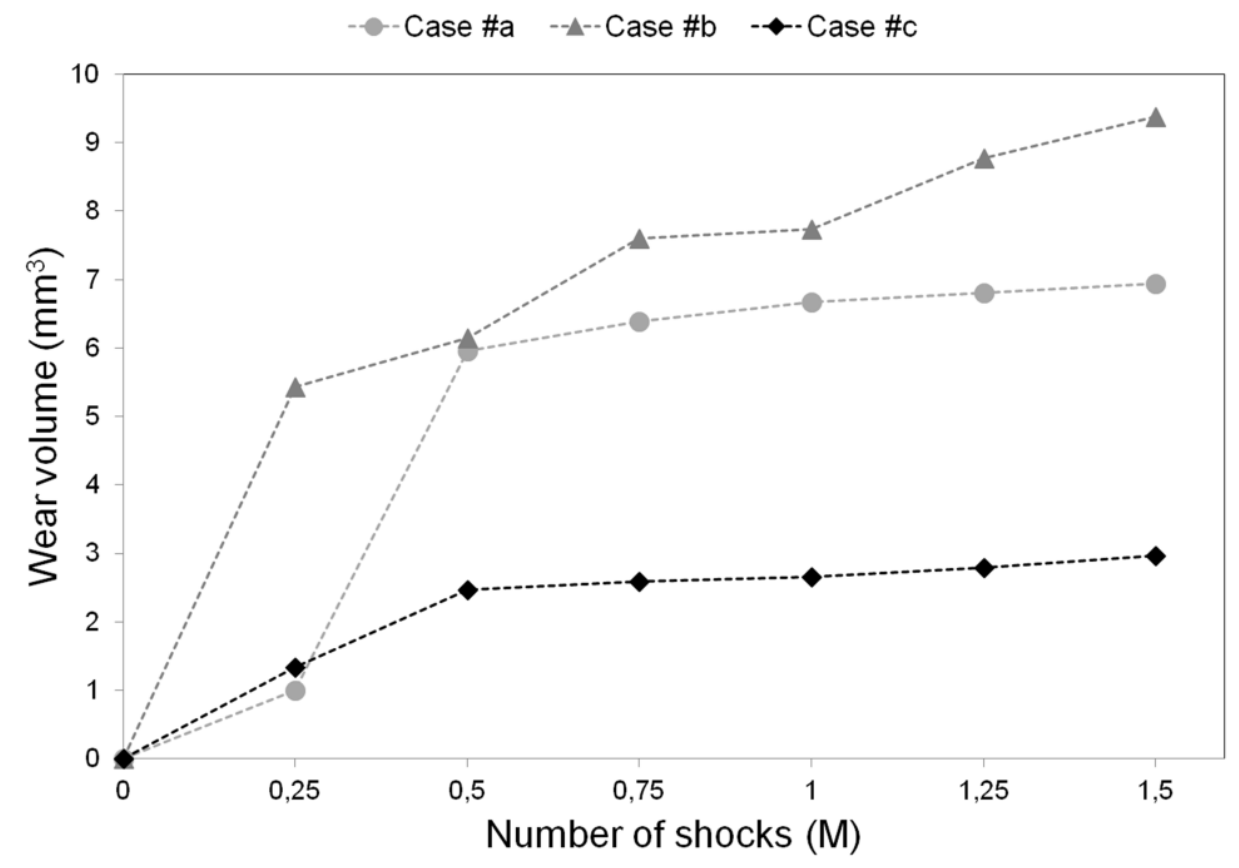

Figure 8: Wear volumes evolution for the three ZTA bearings tested on the shock machine $(9000 \mathrm{~N})$. Two distinct phases were defined from 0 to $0.5 \mathrm{M}$ shocks and from 0.5 to $1.5 \mathrm{M}$ shocks. Identified experimental accidents occurred on cases \#a and \#b.

For the three ZTA bearings tested on the shock machine, the average volumetric-wear rate was calculated for each distinct phase (Figure 9). During the initial phase, the wear rate reached $0.97 \mathrm{~mm}^{3} /$ year while it lowered to $0.22 \mathrm{~mm}^{3} /$ year during the late phase. The overall wear rate 
averaged to $0.46 \mathrm{~mm}^{3} /$ year. A high dispersion was observed among the three tests (in particular during the initial phase) and was attributed to the experimental accidents occurring on cases \#a and \#b.

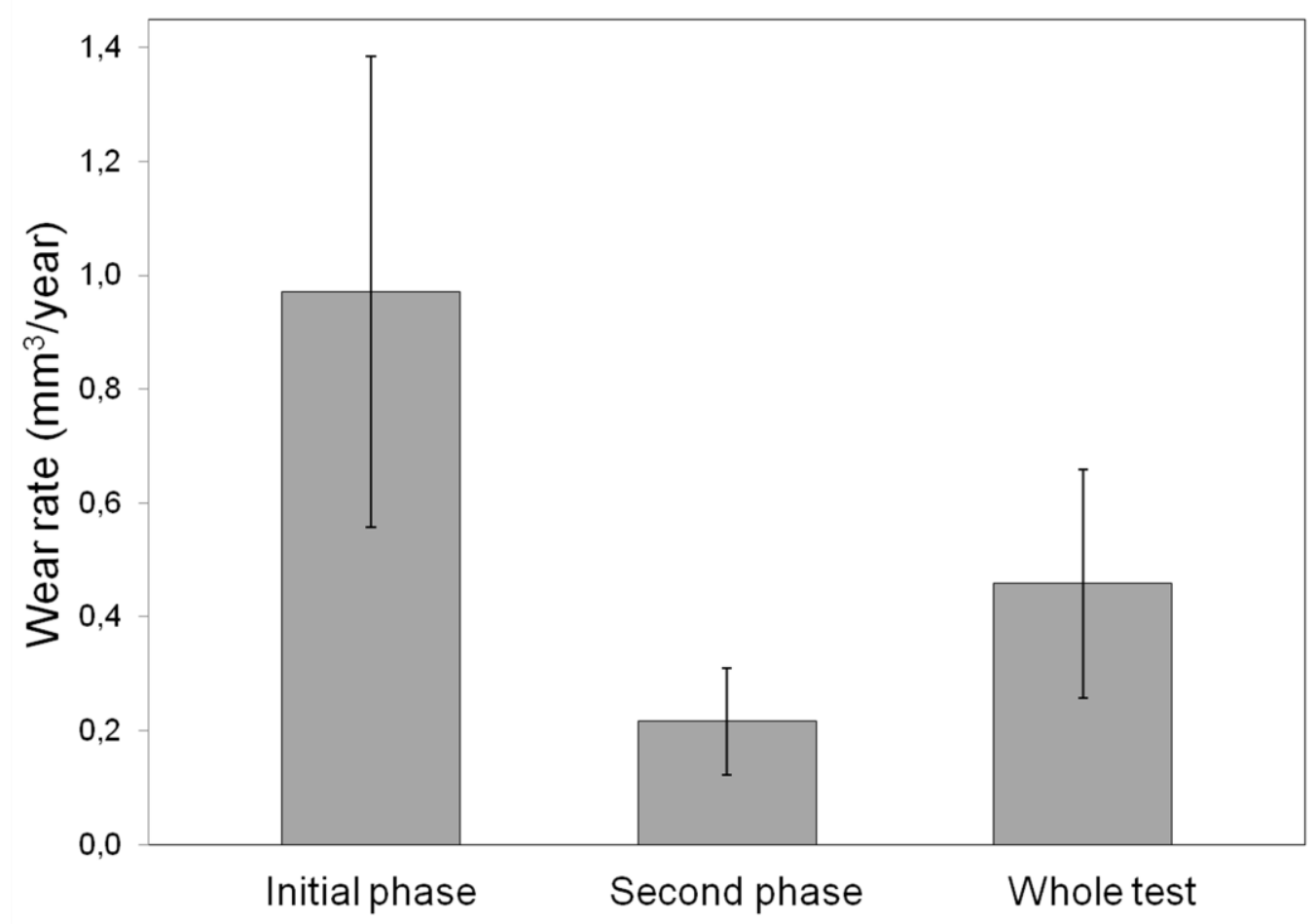

Figure 9: Average volumetric-wear rate calculated for each distinct phase for the three ZTA bearings tested on the shock device at $9000 \mathrm{~N}$ (cases \#a to \#c).

\subsection{Zirconia phase transformation}

Long-term hydrothermal degradation in an autoclave was performed on two distinct ZTA femoral heads that were not submitted to shock degradation. One of the femoral head was tested for small time increments (case \#d) while the other was tested only at long durations (case \#e). A slight increase of the monoclinic content was measured by micro Raman spectroscopy on both ZTA femoral heads (Figure 10). No significant difference was observed between the two test conditions. This suggests that the number of cumulative ageing steps has no effect on the hydrothermal degradation of such components. More important, it is to note that the evolution of monoclinic content in both cases was very low, with less than $5 \%$ variation after 10 hours and less than $10 \%$ after 100 hours. 


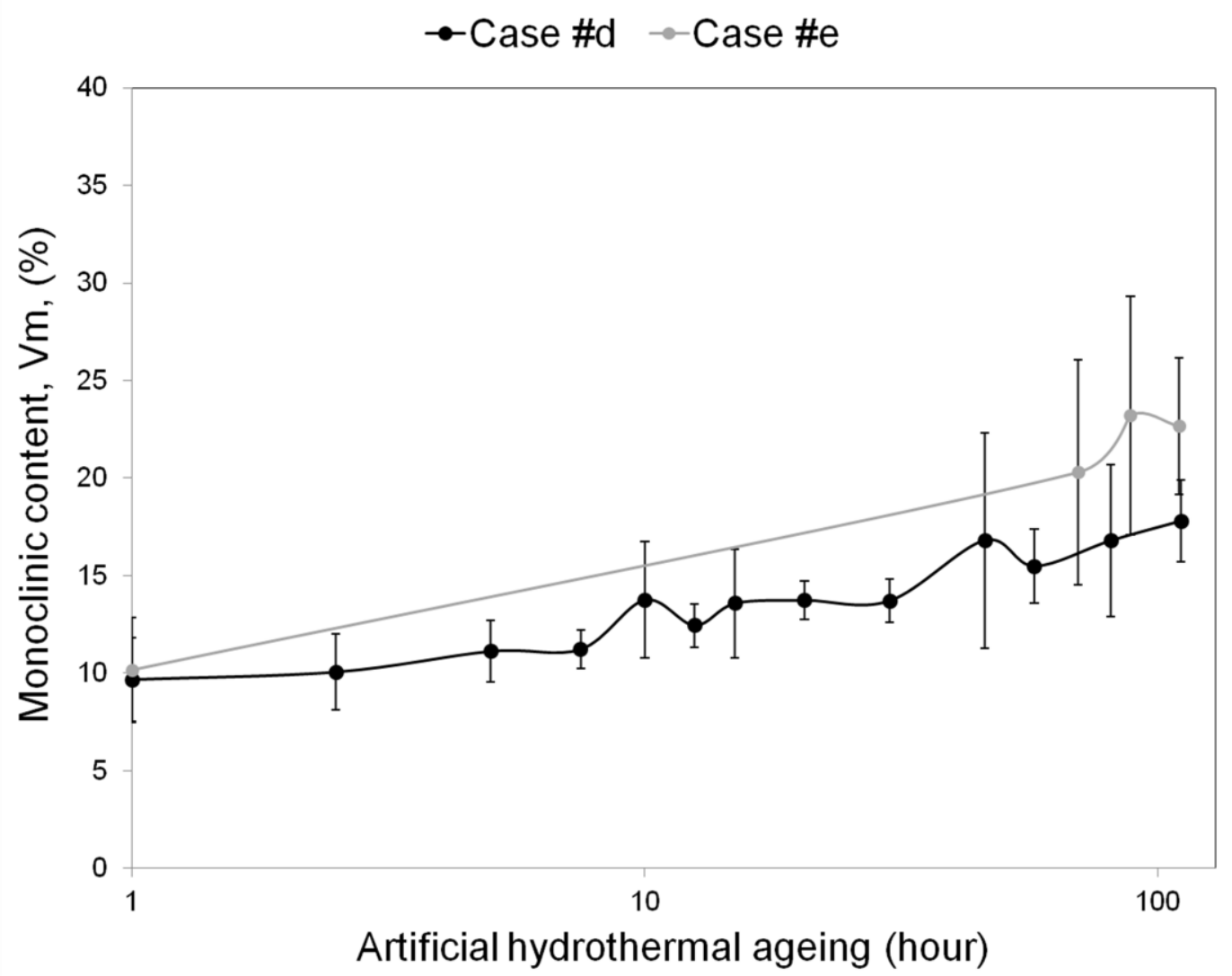

Figure 10: Monoclinic fraction plotted vs. exposure time of hydrothermal ageing in an autoclave and measured by micro Raman spectroscopy on two ZTA femoral heads (cases \#d and \#e). A log scale was applied in order to visualize the evolution of $V_{m}$ during the first alteration cycles.

The zirconia phase transformation was also quantified on the two femoral heads submitted only to shock degradation, cases \#a and \#b (Figure 11). There was no detectable significant phase transformation outside of the wear stripes (i.e. unworn areas) where the monoclinic content, $V_{m}$, averaged to $12 \%$. On the other hand, $V_{m}$ increased within the wear stripes from the first cycles of shocks. The averaged values of $V_{m}$ held between 40 and $45 \%$ for the whole testing time. Compared to the evolution of the wear volume, no distinct evolution phases were observed and no tendency (increase or decrease) was detected with increasing the number of shocks. This indicates that the increase of $V_{m}$ within the wear stripes reached quickly a limit, which we interpret as a maximum transformation before grains detached from the surface to form wear debris. 


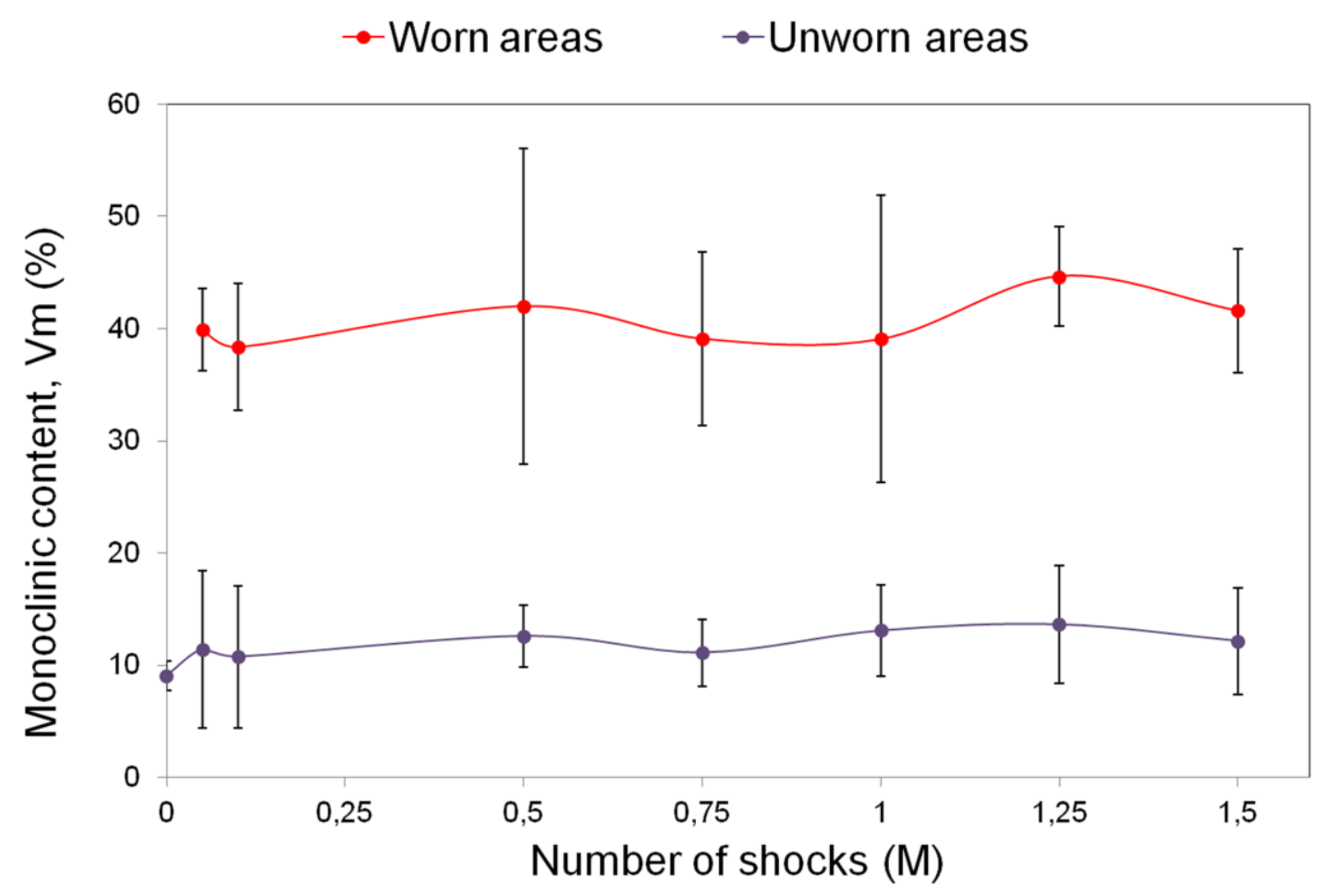

Figure 11: Evolution of the monoclinic content $\left(V_{m}\right)$ as a function of the number of shocks. Averaged values obtained on worn (i.e. within the wear stripes) and unworn areas of the two ZTA bearings tested only on the shock machine at 9000N (cases \#a and \#b).

The evolution of the monoclinic content was assessed regularly along the stripe width (Figure 12). The corresponding stripe depth profile was obtained by $3 D$ profilometry. $V_{m}$ ranged between 40 and $60 \%$ within the stripe and decreased steeply at the edges of the worn areas. This indicates that significant phase transformation occurred strictly within the wear stripes associated with shocks. 


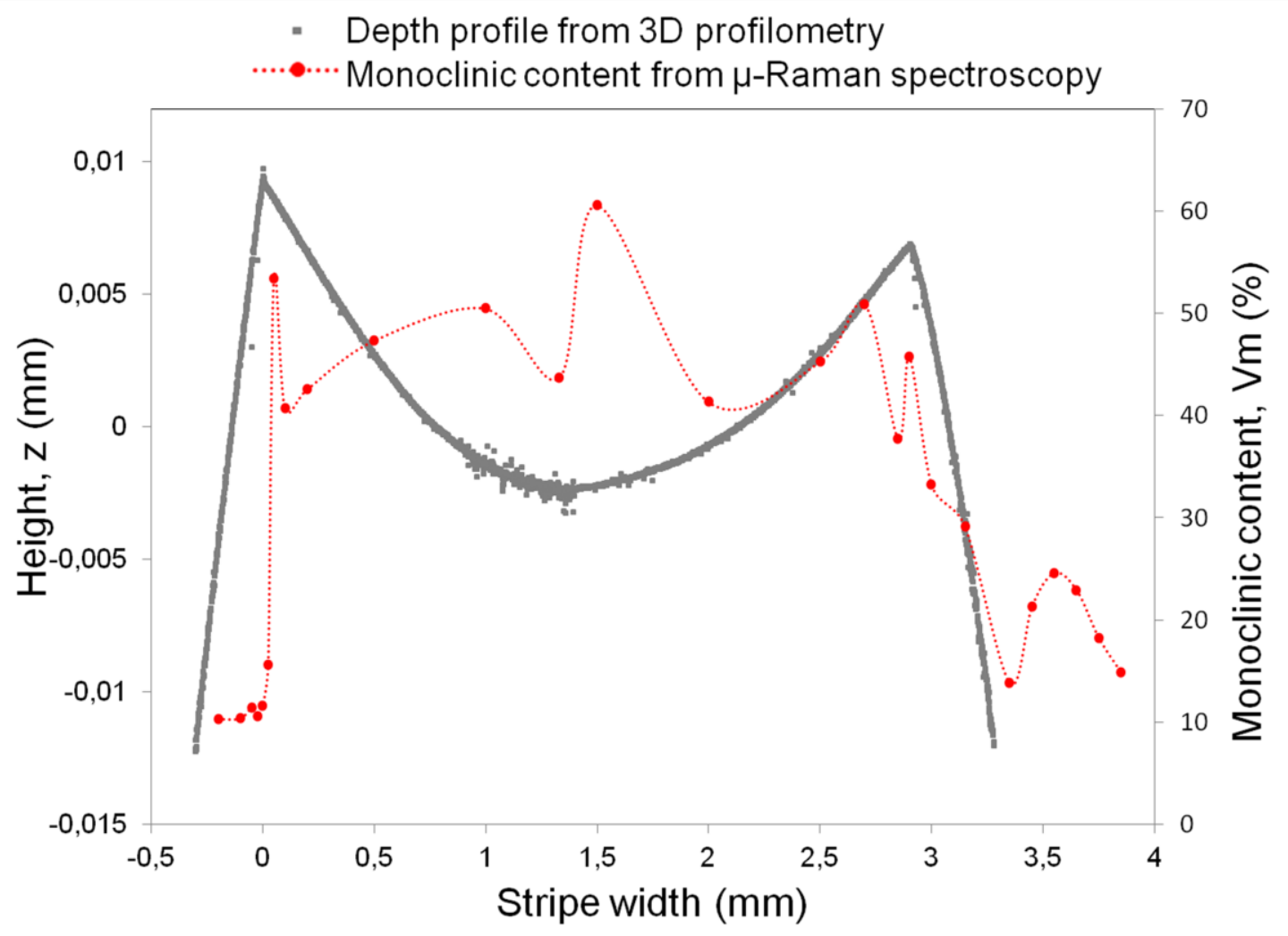

Figure 12: Evolution of the monoclinic content measured along the stripe width by micro Raman spectroscopy and the corresponding stripe depth profile obtained from 3D profilometry. The increase of the monoclinic content was spatially well limited within the stripe, i.e. worn areas.

Finally one prosthetic couple (case \#c) was alternatively subjected to shock and hydrothermal degradation in order to detect a potential combined effect of these two degradation mechanisms. Every 50,000 shocks, both the femoral head and cup were altered for 0.5 hours in an autoclave. No significant increase of the monoclinic content was detected outside of the stripes. Limit values of $V_{m}$ reaching between $40 \%$ and $50 \%$ were measured within the worn areas. No difference was observed compared to cases \#a and \#b (Figure 11), which were submitted only to shocks.

\subsection{Characterization of retrieved implants}

Four ZTA and one yttria stabilized zirconia clinically retrieved implants were studied for comparing the in vivo and in vitro behaviors. Femoral head surfaces display wear areas that can be identified by optical inspection due to lower reflectivity and higher roughness than unworn areas (Figure 13). Their shapes are more diffuse than the regular upper and lower stripes observed on the shocked femoral heads, indicating that the shock area is more dispersed in vivo than in the geometrically constrained experiment. Elliptical wear areas on retrieved implants are sometimes observed, and are reminiscent of the elongated wear areas obtained in the experiments. 


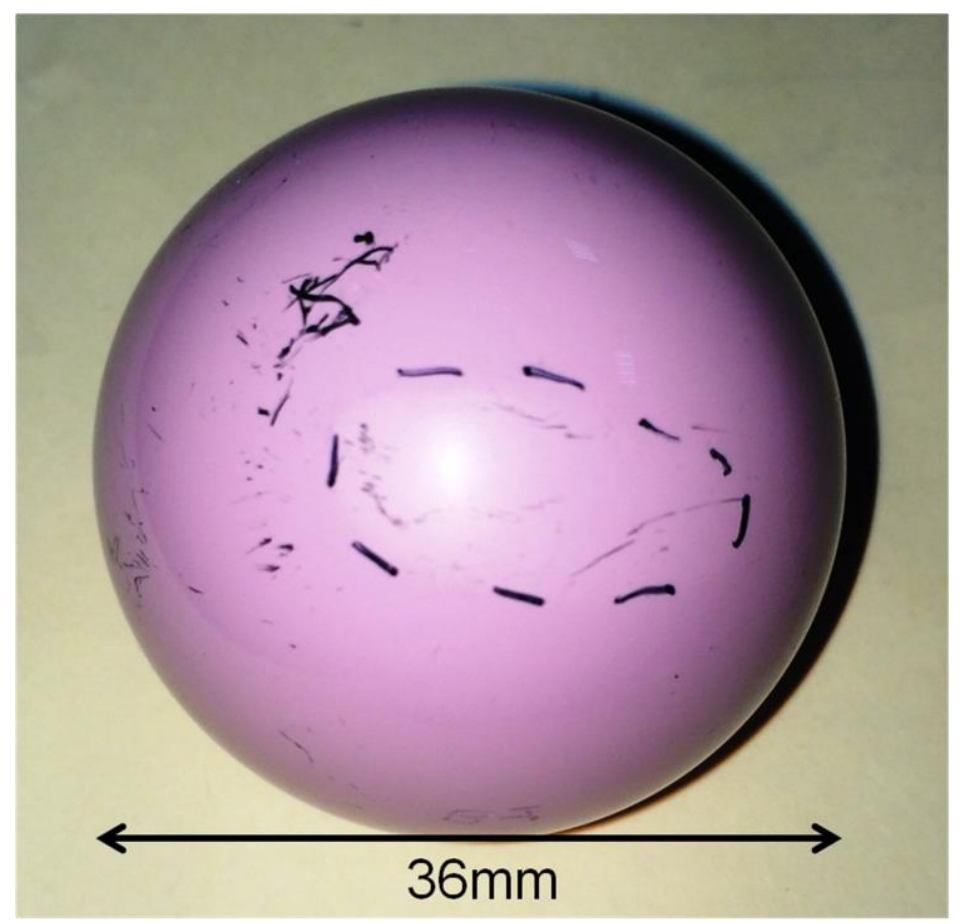

Figure 13: Image of a ZTA retrieved femoral head showing a typical wear stripe pattern detected by optical inspection (case \#1).

Micro Raman spectroscopy and 3D profilometry were employed to investigate the evolution of the monoclinic content and the roughness parameter $S_{a}$ on the retrieved explant surfaces. Both parameters were measured on the as-defined worn and unworn regions (Figure 14). The five retrieved heads showed significantly higher values of $V_{m}$ and $S_{a}$ within the worn areas than outside of them. Since the initial implant surface finishing and monoclinic content are unknown, the absolute $V_{m}$ and $S_{a}$ values are not reliable indicators of wear. The main observation is that the relative difference of $V_{m}$ between worn and unworn zones was relatively similar for the five retrieved implants. An average difference of $21 \pm 2.5 \%$ was measured. On the other hand, the difference in roughness values were scattered among the five components. 


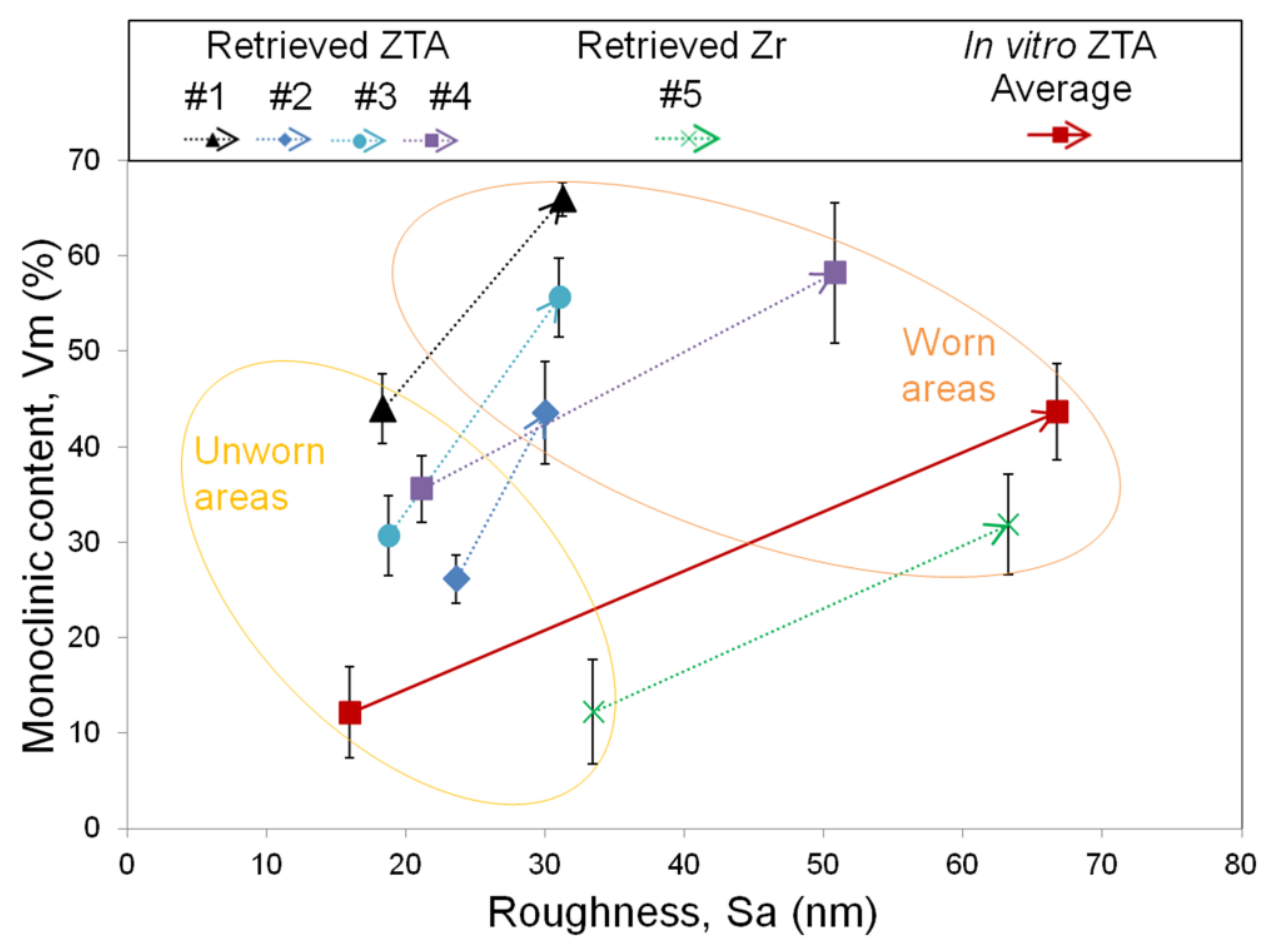

Figure 14: Monoclinic content (\%) plotted vs. surface roughness parameter $S_{a}(\mathrm{~nm})$ and measured separately on the worn and unworn areas. Four ZTA and one yttria stabilized zirconia clinically retrieved femoral heads were studied. The average values obtained from in vitro tests on the shock machine $(9000 \mathrm{~N})$ are indicating for comparison.

\section{Discussion}

\subsection{Wear quantification and mechanisms}

Three ZTA femoral heads and cups have been subjected to extreme shock degradation at $9000 \mathrm{~N}$ on a device specifically designed to reproduce microseparation conditions. The components were submitted to $1.5 \mathrm{M}$ shocks, i.e. 15 simulated in vivo years. Shocks led to the formation of wear stripes on the femoral head surfaces. The surface roughness increased within those areas and remained constant outside of them. This suggests that the sliding phase, which may occur when the components return to their initial position after shock, does not induce wear and is negligible. The SEM observation (Figure 7) of an isolated wear debris revealed mainly inter-granular fracture on ZTA components. This indicates that grain agglomerates have been literally pulled-out during the shock degradation.

Wear was quantified by 3D profilometry and two distinct wear phases were defined. During the first one, both the stripes width and wear volume increased considerably (Figure 8). A slight increase was then noticed up to the end of the test. Some heterogeneity was observed among the three prosthetic couples tested under the same loading conditions and was attributed to experimental accidents occurring during the initial phase. It is worth noting that despite those 
phenomena, the wear volume trends (occurrence of two distinct phases) and the wear mechanisms (surface roughness increase within the wear stripes) were repeatable among the three long-term experiments.

Hip walking simulators are commonly employed to test and predict the hip implants wear performance. Under standard conditions, extremely low volumetric-wear rates characterize Ceramic-on-Ceramic bearings [2]. The microseparation was introduced in hip walking simulator tests in order to better model in vivo effects of both friction and shocks on the femoral heads and cups [8], [18]-[20]. With these improved simulators, the characteristic in vivo damage, e. g. the wear stripe patterns and main wear zones observed on clinically retrieved ceramic implants [21][23], was experimentally reproduced. As a consequence, the volumetric-wear rates measured experimentally increased significantly [24].

Stewart et al. [20] and Clarke et al. [19] respectively reported volumetric-wear rates of 0.16 and $0.2 \mathrm{~mm}^{3} /$ year on ZTA components subjected to hip walking simulators including microseparation. They both observed the occurrence of distinct phases on the wear volume trends. Al-Hajjar et al. [18] reached $0.14 \mathrm{~mm}^{3} /$ year. In this study that focused on the shock device, the wear rate averaged $0.46 \mathrm{~mm}^{3} /$ year (Figure 9). This suggests that the contact force applied here between the two prosthetic components during the shocks $(9000 \mathrm{~N})$ must be significantly higher than the ones applied on hip walking simulators in the previous studies and that are not specified in the literature. Here, severe load conditions were chosen in order to test the wear performance and fracture probability of ZTA prosthetic components in the worst case of shocks. It is worth noting that similar wear stripe patterns were observed on the components tested on hip walking simulators with microseparation and on the shock machine. This suggests that shocks induce the main wear degradation and that standard friction effects occurring on usual hip walking simulators are negligible.

\subsection{Influence of shocks and wear on the zirconia phase transformation}

The zirconia phase transformation from a tetragonal to a monoclinic phase is enhanced by mechanical and chemical stresses. In this study, we evaluated the monoclinic content, $V_{m}$, on the femoral heads subjected to the shock degradation. A significant increase of $V_{m}$ (from 10 to $45 \%$ ) was measured within the wear stripe patterns, which were created by the shocks. No phase transformation was detected outside of them. This indicates that the phase transformation is enhanced by the mechanical stresses induced by shocks.

The increase of $V_{m}$ within the stripes reached quickly a plateau during the first cycles of shocks. Since the stripes width and depth kept increasing during the whole testing time, it suggests that the transformation and wear of zirconia layers on the surface occur at similar rates to produce the observed steady state behavior. The evolution of $V_{m}$ along a stripe width (Figure 12) revealed also the occurrence of a spatial plateau for the phase transformation.

In order to explore the potential combined effects of shocks and hydrothermal ageing on ZTA implants, different in vitro tests have been performed and compared: tests on the shock machine device only, artificial hydrothermal ageing only and a combination of both testing methods (Table 2). The ZTA composites showed little phase transformation by hydrothermal ageing (Figure 10) 
when compared to the transformation increase caused by the mechanical stresses applied during the shocks within the wear stripes. The combination of hydrothermal ageing and shocks had no additional effect on the wear degradation and the phase transformation of prosthetic components. Shocks dominate hydrothermal ageing effects on the ZTA hip implants degradation.

Little is known in the literature on the potential relations between the zirconia phase transformation and microseparation, i.e. the shock degradation. Al-Hajjar et al. [18] did not report any significant increase of $\mathrm{V}_{\mathrm{m}}$ within the wear patterns formed on ZTA heads surface tested on a hip walking simulator including microseparation. On the other hand, Clarke et al. [19] revealed a phase transformation on alumina-zirconia composite bearings. Initially close to $14 \%, \mathrm{~V}_{\mathrm{m}}$ reached a limit value of $30 \%$ within the wear zones. In particular, the increase of $V_{m}$ was faster within the stripe zones, i.e. the zones the most prone to shocks, than on the other main wear areas.

Some comparisons between Clarke's study [19] and the present study can be made. The hypothesis of higher contact forces involved on the shock device than the ones applied on hip walking simulators with microseparation must be confirmed. This could explain the higher amount of the zirconia phase transformation detected within the wear regions in this study (40\%) than in reference [19](30\%). The mechanisms of wear stripe formation may be similar since both studies highlighted the presence of a limit level of the monoclinic content increase. Finally, the weak contribution of the friction effects on the shock device must explain the lack of phase transformation outside of the wear stripes in this study.

In terms of resistance of ceramic materials to the formation and propagation of wear stripes generated by shocks, it is important to notice that the above-mentioned stress-assisted transformation is beneficial to decrease the depth and volume of wear stripes when compared to non-transformable ceramics such as alumina. In previous works, indeed, alumina femoral heads exhibited higher wear volume release than ZTA ones tested under the same conditions [10]. It is also important to note here that none of the ZTA femoral heads broke despite the extreme conditions of shocks imposed during the tests $(9000 \mathrm{~N})$. Toughening mechanisms associated to the phase transformation are supposed to prevent the propagation of cracks, potentially created by shocks and that may be at the origin of grains pulled-out within the wear areas.

\subsection{Comparison between in vivo and in vitro}

This study sought to reproduce experimentally at best the in vivo degradation by focusing on shocks and hydrothermal ageing. The wear degradation and zirconia phase transformation are found to be mainly enhanced by shocks in vitro. Five retrieved femoral heads (four ZTA and one yttria stabilized zirconia bearings, Table 1) were characterized for comparison. Optical inspection of the retrieved head surfaces revealed wider wear tracks, some of which similar in shape (i.e. elliptical shape, Figure13) to the ones created in vitro. The surface roughness parameter $S_{a}$ ranged between 25 and $65 \mathrm{~nm}$ within in vivo worn areas. It reached up to several hundreds of $\mathrm{nm}$ within in vitro wear stripes. The in vivo wear tracks were broader and shallower than the in vitro ones. The mechanical stresses must be more distributed in vivo than in vitro. This could be a consequence of the shock machine rigidity and the absence of movements on it (rotation, flexion, etc.). 
Only few studies reported the presence of wear areas on retrieved alumina-zirconia composites. Clarke et al. [19] analyzed three retrieved heads with detectable main wear zones in which $\mathrm{S}_{a}$ ranged between 55 and $140 \mathrm{~nm}$ and $V_{m}$ reached up to $40 \%$. Lombardi et al. [25] identified stripe wear zones on ZTA heads associated to elevated surface roughness and monoclinic content $\left(\mathrm{S}_{\mathrm{a}}\right.$ and $\mathrm{V}_{\mathrm{m}}$ averaged respectively at $55 \mathrm{~nm}$ and $33 \%$ ). Affatato et al. [26] reported wear and typical wear stripe patterns on alumina and ZTA bearings characterized by an increase of the monoclinic content. In fact, most alumina-zirconia composite components are recent and this limits the current follow-up studies. It must be kept in mind that the appearance of the elliptic wear stripe patterns is better documented on alumina femoral head surfaces [21]-[23]. In this study, the worn areas were first carefully defined and separated from the rest of the retrieved head surfaces by optical inspection before performing a detailed surface characterization.

A precise quantification of the local monoclinic content was performed on the five retrieved heads. A constant difference of about $20 \%$ was measured between the as-defined worn and unworn zones and the absolute maximum value reached up to 65\% (Figure 14). The three femoral heads experimentally submitted to the shock degradation $(9000 \mathrm{~N})$ also revealed a constant difference between the worn and unworn regions of $30 \%$ (the absolute maximum value reached around $60 \%$, Figure 11 and Figure 12). The initial $V_{m}$ values depend on the specific composition and manufacturing of each implant. It is thus not practical to compare absolute $\mathrm{V}_{\mathrm{m}}$ values between in vivo and in vitro components or with the ones reported in the literature. On the other hand, differences of $V_{m}$ between worn and unworn areas seem consistent among measurements on in vitro and in vivo ceramic heads.

The observation of a constant difference between the two types of area on in vitro as well as in vivo components suggests that the mechanical mechanisms enhancing the zirconia phase transformation are well-reproduced experimentally through the tests on the shock device. This implies that high mechanical stresses are locally correctly applied, i.e. only within the wear stripes. Secondly, the quantitative comparison of those two relative differences $(20 \%$ and $30 \%$ for respectively in vivo and in vitro components) confirms that we chose to experimentally study the worst case of shock degradation $(9000 \mathrm{~N})$. It is worth noting that no fracture has been observed over all the in vitro components tested under those severe conditions.

\section{Conclusion}

Through the comparison of in vitro tests and retrieved implants, this study highlights major results relating to the wear mechanisms of hip bearings and the degradation of zirconia toughened alumina components:

1. The wear degradation is characterized by the formation of typical wear stripe patterns, which are reproduced through in vitro tests on the shock device.

2. A new method specifically developed to measure low wear volumes is successfully employed on the spherical shape of femoral heads and reveals in vitro volumetric-wear rates in agreement with the ones reported in the literature. 
3. The ZTA material shows little transformation during artificial hydrothermal degradation. Therefore only mechanical stresses applied during shock degradation are at the origin of the monoclinic content increase detected within the wear stripe patterns on in vitro components.

4. Wear regions are precisely defined on retrieved femoral heads and also reveal significant in vivo zirconia phase transformation. This also suggests that the transformation is mainly enhanced by mechanical stresses on wear areas of the hip joint implants.

5. Correlations between the in vivo and in vitro wear degradation indicate that the shock machine is an adequate alternative device to standard hip walking simulators in order to reproduce at best the in vivo environment.

\section{Acknowledgments}

This work was supported by the Region Rhône-Alpes / ARC2. The authors wish to thank Tornier, Inc company, Pr. Affatato from Medical Technology Laboratory (Rizzoli Orthopaedic Institute, Bologna, Italy) and Dr. Bertrand Boyer (MD, Ph.D) from Chirurgie Orthopédique et Traumatologie service (CHU Saint-Etienne, France) for providing retrieved implants; Dr. Gilles Montagnac from Laboratoire de Géologie de Lyon (CNRS, ENS Lyon, France) for his help with the Raman spectroscopy; Albert Boyer for the technical collaboration; Serf ${ }^{\mathrm{TM}}$ and CeramTec AG companies for supporting this study. The Raman spectroscopy facility at LGL ENS de Lyon is a national instrument funded by the Institut National des Sciences de I'Univers.

\section{References}

[1] P. Boutin, "Total arthroplasty of the hip by fritted aluminum prosthesis. Experimental study and 1st clinical applications ", Rev. Chir. Orthop. Reparatrice Appar. Mot., vol. 58, n 3, p. 229-246, déc. 1971.

[2] A. Essner, K. Sutton, et A. Wang, " Hip simulator wear comparison of metal-on-metal, ceramic-onceramic and crosslinked UHMWPE bearings ", Wear, vol. 259, nº 7-12, p. 992-995, juill. 2005.

[3] C. Piconi et R. M. Streicher, " 40 Years of Ceramic-on-Ceramic THR Bearings ", Semin. Arthroplasty.

[4] S. M. Kurtz, S. Kocagöz, C. Arnholt, R. Huet, M. Ueno, et W. L. Walter, "Advances in zirconia toughened alumina biomaterials for total joint replacement ", J. Mech. Behav. Biomed. Mater., vol. 31, p. 107-116, mars 2014.

[5] J. Chevalier, B. Cales, et J. M. Drouin, "Low-temperature aging of Y-TZP ceramics ", J. Am. Ceram. Soc., vol. 82, nº 8, p. 2150-2154, août 1999.

[6] «Implants for surgery - wear of total hip-joint prostheses. Part 1: Loading and displacement parameters for wear-testing machines and corresponding environmental conditions for test. ISO standard 14241-1:2002. " .

[7] D. A. Dennis, R. D. Komistek, E. J. Northcut, J. A. Ochoa, et A. Ritchie, " "In vivo" determination of hip joint separation and the forces generated due to impact loading conditions ", J. Biomech., vol. 34, $n^{\circ} 5$, p. 623-629, mai 2001.

[8] J. Nevelos, E. Ingham, C. Doyle, R. Streicher, A. Nevelos, W. Walter, et J. Fisher, " Microseparation of the centers of alumina-alumina artificial hip joints during simulator testing produces clinically relevant wear rates and patterns ", J. Arthroplasty, vol. 15, n 6, p. 793-795, sept. 2000. 
[9] J. Uribe, J. Geringer, et B. Forest, " Shock machine for the mechanical behaviour of hip prostheses: a description of performance capabilities ", Lubr. Sci., vol. 24, n² 2, p. 45-60, mars 2012.

[10] J. Uribe, J. Geringer, L. Gremillard, et B. Reynard, « Degradation of alumina and zirconia toughened alumina (ZTA) hip prostheses tested under microseparation conditions in a shock device », Tribol. Int., vol. 63, p. 151-157, juill. 2013.

[11] J. Uribe, J. Hausselle, J. Geringer, et B. Forest, «Finite Element Modelling of Shock-Induced Damages on Ceramic Hip Prostheses ॥, ISRN Mater. Sci., vol. 2011, p. 1-14, 2011.

[12] J. Chevalier, L. Gremillard, et S. Deville, " Low-temperature degradation of Zirconia and implications for biomedical implants", in Annual Review of Materials Research, vol. 37, Palo Alto: Annual Reviews, 2007, p. 1-32.

[13] J. Hausselle, "Etude de la dégradation par chocs de têtes et cupules de prothèses de hanche en biocéramique », Ecole Nationale Supérieure des Mines de Saint-Etienne, 2007.

[14] «Implants for surgery - Ceramic materials based on yttria-stabilitzed tetragonal zirconia (Y-TZP). ISO standard 13356:2008 ». .

[15] «A. Jennings (2011) Sphere Fit (least (http://www.mathworks.com/matlabcentral/fileexchange/34129), MATLAB Central File Exchange. Retrieved January, $2014 »$. .

[16] D. R. Clarke et F. Adar, " Measurement of the Crystallographically Transformed Zone Produced by Fracture in Ceramics Containing Tetragonal Zirconia ", J. Am. Ceram. Soc., vol. 65, n 6, p. 284-288, juin 1982.

[17] V. Mazet, C. Carteret, D. Brie, J. Idier, et B. Humbert, "Background removal from spectra by designing and minimising a non-quadratic cost function ", Chemom. Intell. Lab. Syst., vol. 76, $\mathrm{n}^{\circ} 2$, p. 121-133, avr. 2005.

[18] M. Al-Hajjar, L. M. Jennings, S. Begand, T. Oberbach, D. Delfosse, et J. Fisher, "Wear of novel ceramic-on-ceramic bearings under adverse and clinically relevant hip simulator conditions ", J. Biomed. Mater. Res. B Appl. Biomater., vol. 101, nº 8, p. 1456-1462, nov. 2013.

[19] I. C. Clarke, D. D. Green, P. A. Williams, K. Kubo, G. Pezzotti, A. Lombardi, A. Turnbull, et T. K. Donaldson, " Hip-simulator wear studies of an alumina-matrix composite (AMC) ceramic compared to retrieval studies of AMC balls with 1-7 years follow-up », Wear, vol. 267, nº 5-8, p. 702-709, juin 2009.

[20] T. D. Stewart, J. L. Tipper, G. Insley, R. M. Streicher, E. Ingham, et J. Fisher, « Long-term wear of ceramic matrix composite materials for hip prostheses under severe swing phase microseparation ", J. Biomed. Mater. Res. B Appl. Biomater., vol. 66B, n² 2, p. 567-573, août 2003.

[21] E. A. Magnissalis, T. A. Xenakis, et C. Zacharis, "Wear of retrieved ceramic THA components - four matched pairs retrieved after 5-13 years in service ", J. Biomed. Mater. Res., vol. 58, n ${ }^{\circ}$ 5, p. 593598, janv. 2001.

[22] J. E. Nevelos, E. Ingham, C. Doyle, J. Fisher, et A. B. Nevelos, « Analysis of retrieved alumina ceramic components from Mittelmeier total hip prostheses ", Biomaterials, vol. 20, $\mathrm{n}^{\circ} 19$, p. 1833-1840, oct. 1999.

[23] W. L. Walter, G. M. Insley, W. K. Walter, et M. A. Tuke, « Edge loading in third generation alumina ceramic-on-ceramic bearings: Stripe wear », J. Arthroplasty, vol. 19, nº 4, p. 402-413, juin 2004.

[24] T. Stewart, J. Tipper, R. Streicher, E. Ingham, et J. Fisher, " Long-term wear of HIPed alumina on alumina bearings for THR under microseparation conditions ", J. Mater. Sci. Mater. Med., vol. 12, $\mathrm{n}^{\circ}$ 10-12, p. 1053-1056, déc. 2001.

[25] A. V. Lombardi, K. R. Berend, B. E. Seng, I. C. Clarke, et J. B. Adams, " Delta Ceramic-on-Alumina Ceramic Articulation in Primary THA: Prospective, Randomized FDA-IDE Study and Retrieval Analysis ", Clin. Orthop. Relat. Res., vol. 468, n² 2, p. 367-374, nov. 2009. 
[26] S. Affatato, E. Modena, A. Toni, et P. Taddei, "Retrieval analysis of three generations of Biolox ${ }^{\circledR}$ femoral heads: Spectroscopic and SEM characterisation ", J. Mech. Behav. Biomed. Mater., vol. 13, p. 118-128, sept. 2012. 